\title{
Equatorial atmosphere measurements obtained with the sounding rocket grenade experiment
}

\author{
F. de Mendonça, J. H. Sobral, and D. B. Rai \\ Comissāo Nacional de Atividades Espaciais, São José dos Campos, São Paulo, Brazil
}

(Received April 25, 1969.)

\begin{abstract}
Under a grenade series of experiments with sounding rockets made at Barreira do Inferno, Natal $\left(5.6^{\circ} \mathrm{S}, 35^{\circ} \mathrm{W}\right), 19$ successful launchings have yielded useful data on the upper stratosphere and the mesosphere during the period August 7, 1966, to March 5, 1968. These experiments covered the height range of about $35-95 \mathrm{~km}$ and were supplemented by radiosonde data from 19 balloons that provided data up to approximately $35 \mathrm{~km}$. Also, data from 29 meteorological rockets with an upper limit of $60 \mathrm{~km}$ are available for the period September 14, 1966, to July 24,1968 . Only 2 of these 29 launchings were instrumented for temperature measurements. Data on winds, temperatures, and densities have been obtained and analyzed from the rocket-grenade and balloon experiments. Some features of the wind and temperature distributions in the upper stratosphere and mesosphere are discussed. Extremely low mesopause temperatures of the order of $130^{\circ} \mathrm{K}$ were noticed in early summer at about $90 \mathrm{~km}$. The temperature at this height was found to be higher in winter than in summer. A correlation between temperature at $40 \mathrm{~km}$ and absorption of cosmic noise at $30 \mathrm{MHz}$ is also presented as a probable evidence of stratosphere-ionosphere coupling.
\end{abstract}

\section{INTRODUCTION}

The object of this paper is to present and discuss the results of some rocket-grenade experiments made at Natal, Brazil, for measuring winds, temperature, and density in the stratosphere. These data have been supplemented by balloon radiosonde and meteorological rocket observations whenever available. The rocket-grenade experiments consisted of a series of launchings of Nike-Cajun rockets. Each payload included 19 grenades that exploded at predetermined intervals, the first exploding at approximately $35 \mathrm{~km}$ and the last at about $95 \mathrm{~km}$. The sound waves from the explosions were detected by the ground equipment, consisting of a tracking system and a sound ranging station. The tracking system provided the information necessary to determine the time and position of each grenade explosion, and the sound ranging station provided the data necessary to determine the time and direction of the sound arrival at ground level.

The trackings are performed by two ground systems. One is the DOVAP (Doppler velocity and position), which uses the Doppler frequency shift of a $\mathrm{CW}$ signal transmitted by a ground transmitter. The

Copyright (C) 1969 by the American Geophysical Union.
Doppler shift between the direct wave and the returned wave from the rocket permits us to calculate the radial velocity and therefore the radial distance by simple integration. The other system used is the single station interferometer (SSD-RADINT), which combines a Doppler receiver with two interferometer systems to provide the radial distance and two direction cosines of the rocket position.

The evaluation of the desired parameters was then made by means of (1) the time and position of each grenade explosion; (2) the time and direction of sound arrivals; and (3) the complementary data up to the height of the first grenade explosion.

Average horizontal winds and sound velocity between two consecutive explosions are directly derived from the data mentioned above by using the raytracing technique. The temperature is derived from the sound velocity, and finally the pressure is extrapolated by using temperature data. These two last data are in turn combined to give the density data.

The ionospheric absorption data were obtained by means of a riometer located at CNAE. We used a frequency of $30 \mathrm{MHz}$ which is low enough to be sensitive to the nondeviative absorption effects to the lower ionosphere and yet is sufficiently high for detection of signals even under disturbed ionospheric conditions. 


\section{ROCKET-GRENADE ACCURACY}

The rocket-grenade technique for measuring meteorological parameters presents errors that are variable with height. It is known that the accuracy of the results is limited by the errors that appear in measuring arrival times of the sound waves. Analysis has shown that the magnitude of the errors in the height range of $35-75 \mathrm{~km}$ is $\pm 3^{\circ} \mathrm{K}$ in temperature, $\pm 5 \mathrm{~m} / \mathrm{sec}$ in wind speed, and $\pm 15^{\circ}$ in wind direction. In the height range $75-95 \mathrm{~km}$, the corresponding errors for temperature and wind speed are $\pm 10^{\circ} \mathrm{K}$ and $\pm 15 \mathrm{~m} / \mathrm{sec}$, respectively.

\section{UPPER TROPOSPHERIC AND STRATOSPHERIC CIRCULATION}

The time-height cross section at Natal for the period January 1966 to July 1968 is presented in Figure 1. We can see that two distinct groups of easterlies prevail, one extending from the ground up to the lower stratosphere, and the other beginning 5 to $10 \mathrm{~km}$ after the first group and reaching up to the upper stratosphere.

The easterlies prevail in the middle stratosphere but change to westerlies once each year during the period March-May. This is evidence of a reversal in the stratospheric circulation. We conclude then that from 25 to $60 \mathrm{~km}$ the easterlies prevail during $75 \%$ of the year. A tendency for the reversal is also observable during October; however, this reversal is less pronounced than the March-May reversal.

The easterlies are generally much stronger than the westerlies up to $60 \mathrm{~km}$. The maximum velocity for the easterlies was found to be $70 \mathrm{~m} / \mathrm{sec}$ between 40 and $50 \mathrm{~km}$ late in January 1967, whereas the maximum velocity for the westerlies was found to be about $40 \mathrm{~m} / \mathrm{sec}$ between 50 and $60 \mathrm{~km}$ during the reversal periods.

Regarding the rocket-grenade experiments, 7 groups of launchings were made in a 11/2-year period, with a total of 19 launchings. From these experiments we can observe that easterly winds prevailed above $80 \mathrm{~km}$.

The meridional components were found to be much steadier than the zonal components up to 80 $\mathrm{km}$. Beyond this height great variations started to appear. The maximum velocities were $140 \mathrm{~m} / \mathrm{sec}$ for southerlies at $87 \mathrm{~km}$ and $170 \mathrm{~m} / \mathrm{sec}$ for northerlies at $90 \mathrm{~km}$ in midwinter.

\section{DENSITIES}

The densities have been compared with $C I R A$
[1965] models. For this purpose the grenade launchings have been divided again into 7 groups. An individual series consisted of experiments performed within one to three consecutive days, as shown in Table 1. The densities were computed and averaged within each group and then compared with the CIRA models. The corresponding CIRA models used for comparison with our data are also shown in Table 1.

To investigate the density profiles, the relative deviation of the experimental values with respect to CIRA values have been computed and are shown in Figure 2. About $85 \%$ of the experimental values were smaller than the standard ones. However, about $78 \%$ of these negative deviations were found to lie between -5 and $-20 \%$. Two factors might have contributed toward these deviations: first, we did not have a proper latitudinal model (Natal is at $5.9^{\circ} \mathrm{S}$ ), but this would not contribute more than a $2 \%$ deviation; second, comparisons could be made only for the first day of each month. In view of these two sources of deviations and the errors in the experimental

TABLE 1. Launchings arranged according to groups

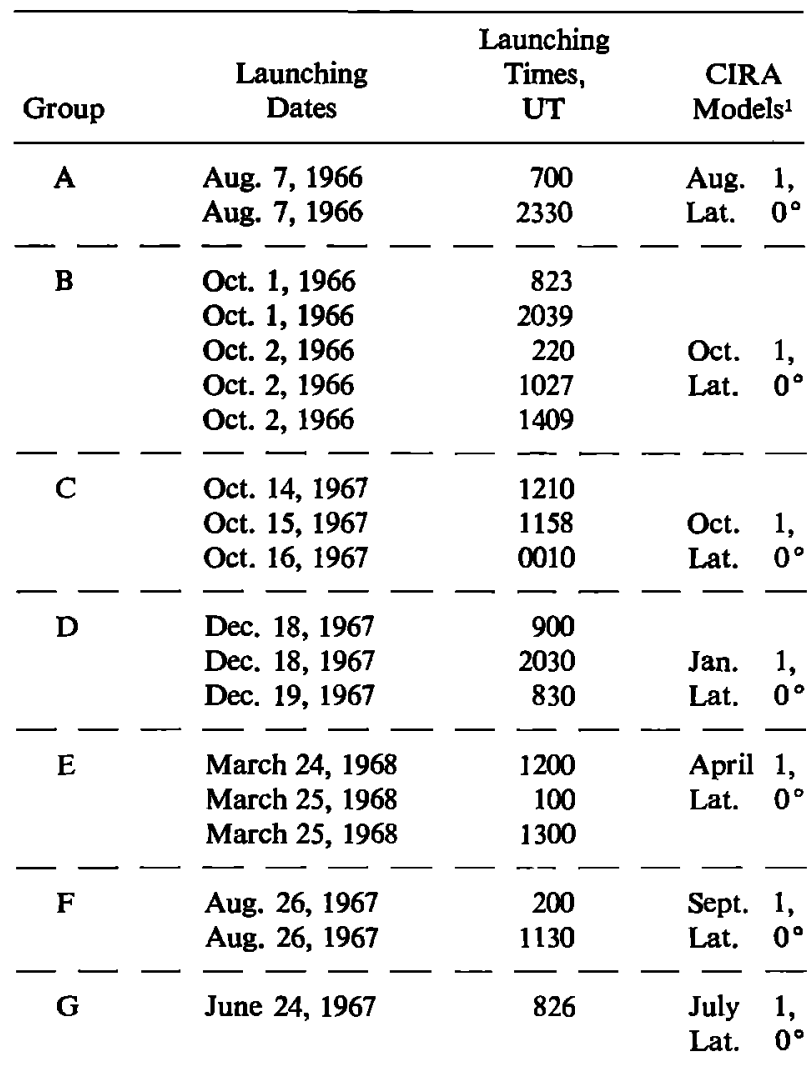

1 CIRA models chosen for comparison with experimental data. 


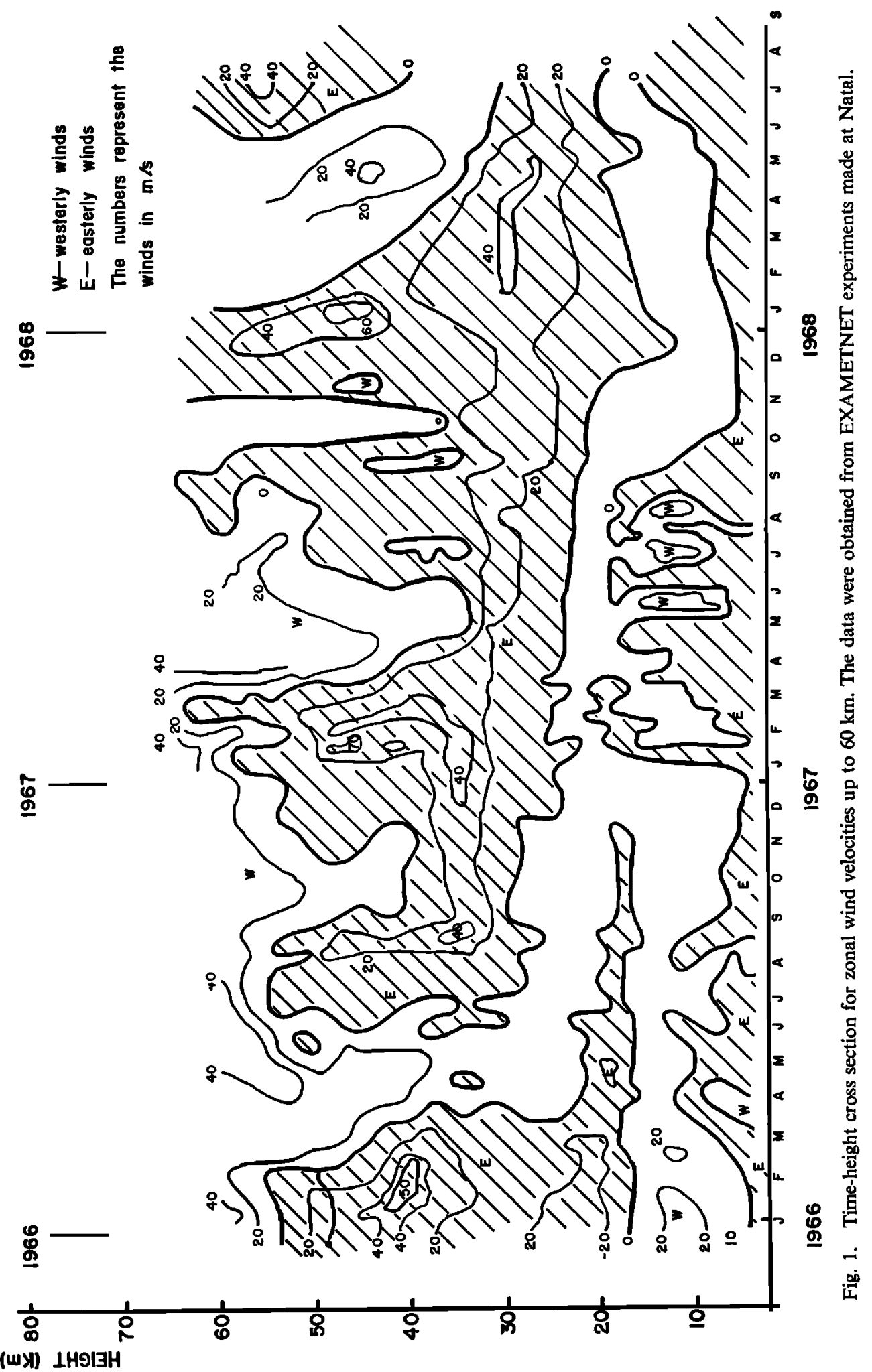




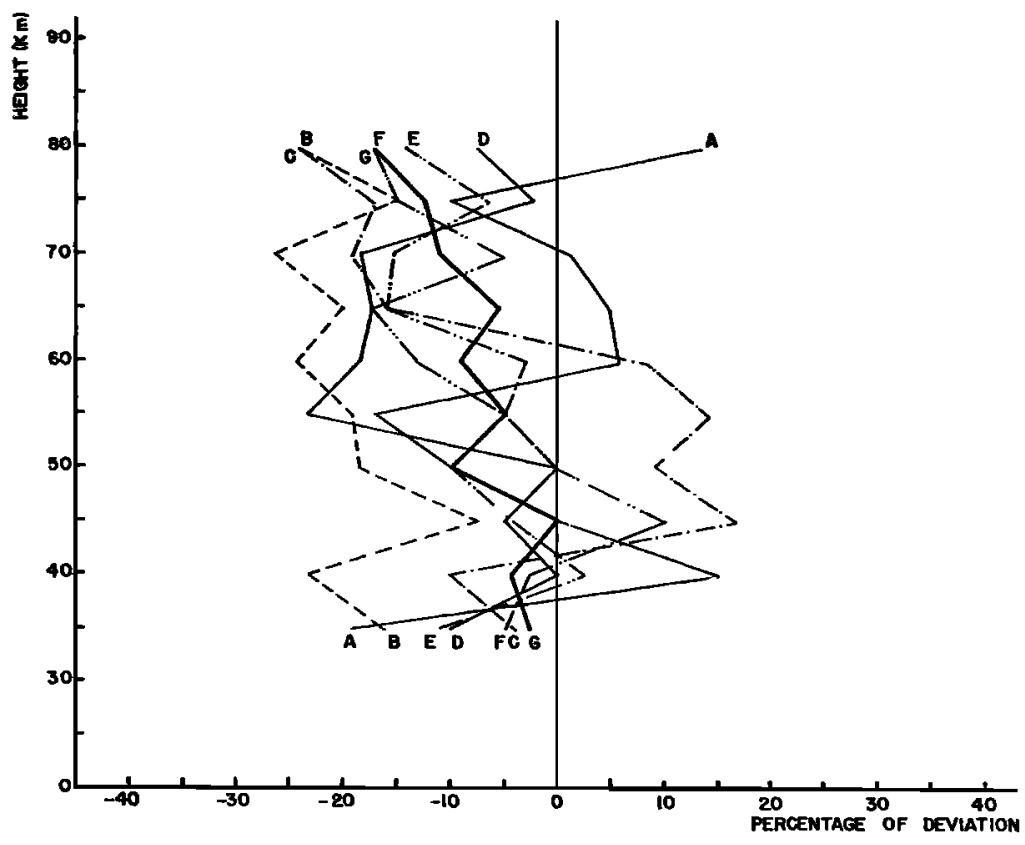

Fig. 2. Deviations from standard CIRA models for pressure. Percentage numbers represent the deviations of the experimental values from the CIRA values, that is [(grenade value - CIRA value)/CIRA value] $X 100$. The letters represent the groups to which the profiles belong (see Table 1).

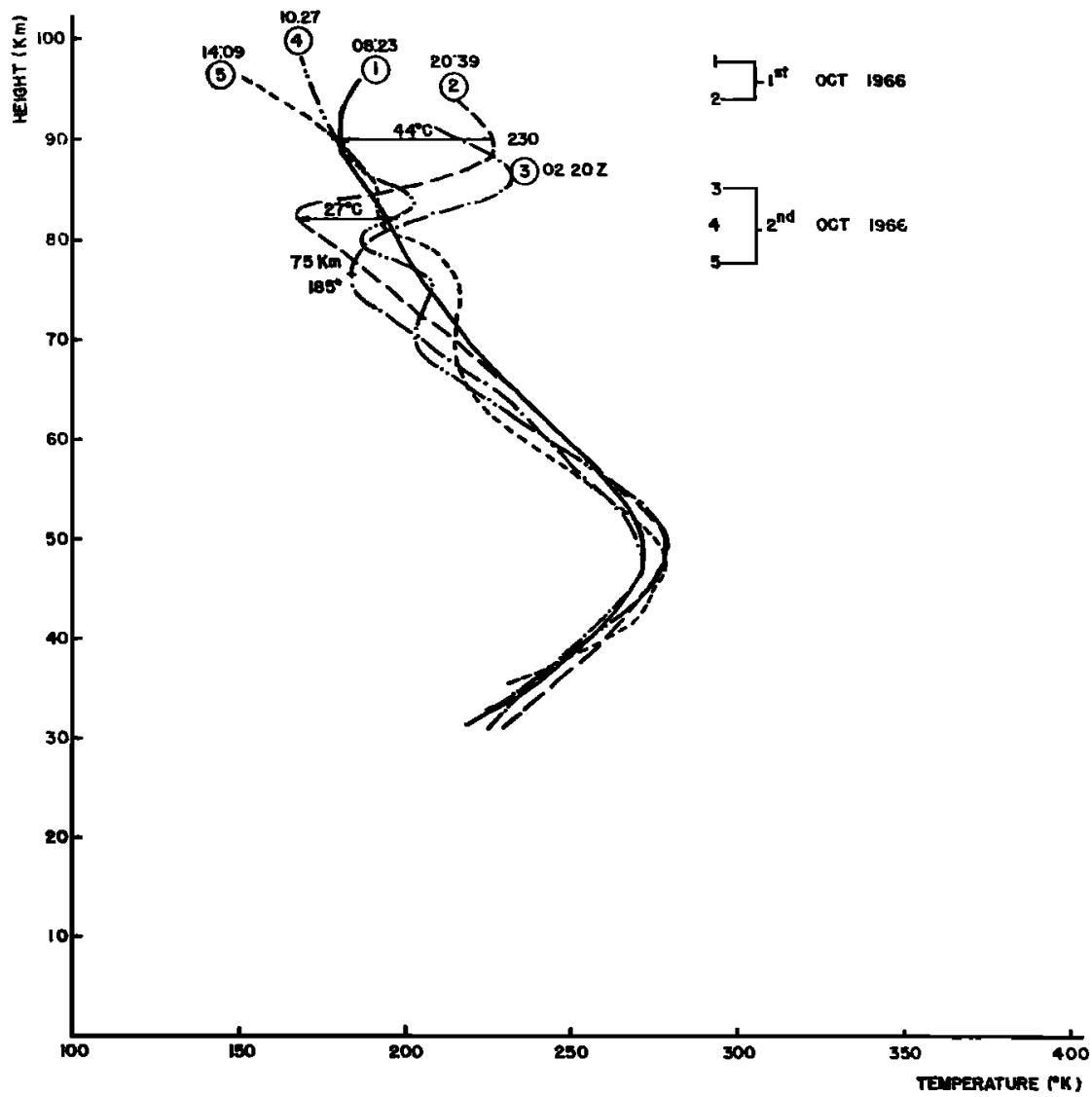

Fig. 3. Temperature-height curves for five experiments; curves are adjusted over the respective experimental data. The numbers indicate the order in which the experiments occurred. Numbers 1 and 2 are from October 1, 1966;3, 4, and 5 are from October 2, 1966. 
measurements, the mentioned deviations must be regarded as insignificant.

The deviations of the density relative to standard values appeared to be random with regard to time. We can see, for example, that groups $A$ and $F$ (Table 1) present completely different types of variations, although both of them pertain to the same month (October) of two consecutive years (1966 and 1967).

The temperature changes through the day were not significant except for October 2, 1966, when the densities at midnight were found to be smaller by more than $40 \%$ than those at midday and sunrise.

\section{TEMPERATURE PROFILES FROM GROUND UP TO $90 \mathrm{KM}$}

Again, the 7 groups mentioned in the two previous sections were used, but for reasons referred to above they could not be viewed through a large time scale; only the diurnal variations can be examined more precisely.
Temperature profiles obtained from 5 experiments made in 2 days are represented in Figure 3. We can see that temperature variations became actually significant only above $60 \mathrm{~km}$. The minimum temperature variations occurred at about $50 \mathrm{~km}$, corresponding to the stable maximum. On the other hand, large temperature variations can be seen in Figure 3. These variations are mainly above $60 \mathrm{~km}$. In a time interval of 12 hours, a decrease of about $27^{\circ} \mathrm{C}$ was found at $82 \mathrm{~km}$. Notwithstanding this abrupt decrease, a steeper decrease of $44^{\circ} \mathrm{C}$ was found at $90 \mathrm{~km}(8 \mathrm{~km}$ above the maximum negative variation), after which the temperature continued to increase smoothly as its height decreased, resulting in a new maximum of $232^{\circ} \mathrm{K}$ at $85 \mathrm{~km}$ and a minimum of $185^{\circ} \mathrm{K}$ at $75 \mathrm{~km}$. Afterward, the trend of the variations was to revert to the first profile.

Average temperatures for each group were computed and the results displayed in Figure 4, where we can observe also minimum temperature variations occurring in the mesopeak and maximum varia-
Fig. 4. Each curve represents the average temperature-height data for one group (see Table 1). The curves have been adjusted over the respective experimental data.

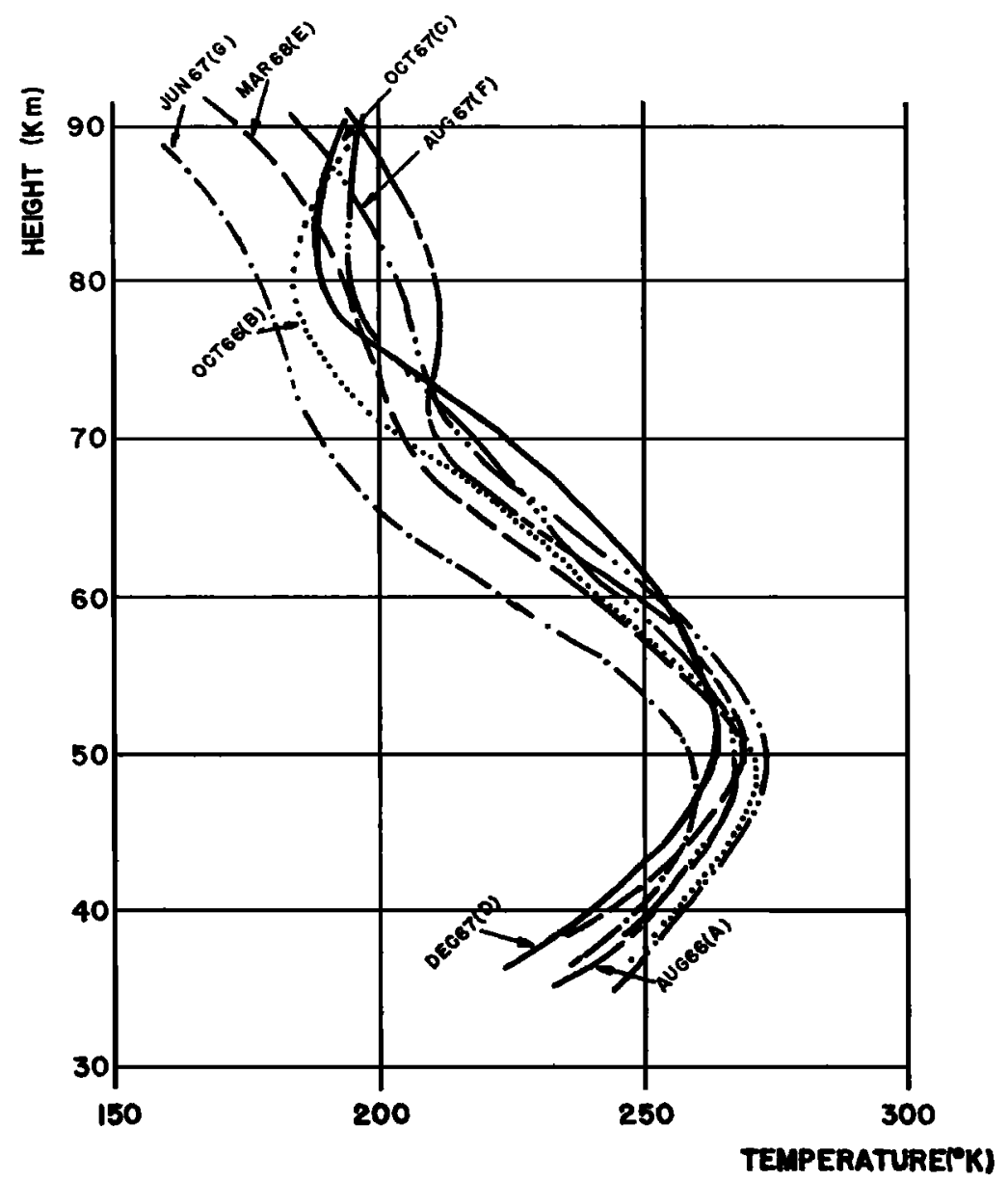


tions occurring around $80 \mathrm{~km}$. Like the diurnal variation mentioned above, more significant variations occurred only above $60 \mathrm{~km}$. We conclude that the diurnal and seasonal temperature variations are similar. The variations are minimum at the mesopeak and increase gradually with height.

An extremely low temperature of $130^{\circ} \mathrm{K}$ was found at $90 \mathrm{~km}$ on October 2, 1966 (Figure 5). The temperature profile from this experiment appeared to be fairly consistent. Although this low value could be partly due to the increasing experimental error with height, this decrease in the mesopause temperature seems real.

Similar low temperatures were also found at Fort Churchill on August 7, 1966, and June 17, 1966, and at Point Barrow on August 15, 1966, and June 17,1966 , where temperatures of the order of $120^{\circ}$ to $140^{\circ} \mathrm{K}$ occurred at approximately $90 \mathrm{~km}$ [Nordberg et al., 1965].

The difference between theoretical and experimental values of sunrise - sunset temperatures plotted against height are shown in Figure 6. A steep temperature variation is found between 70 and 80 $\mathrm{km}$. This occurred because of a sudden decrease of temperature during sunrise at this level. We can see that there is practically no agreement in the phase of the two profiles. The theoretical profile, made by Lindzen [1967], is based on a theory of thermally driven tide in the atmosphere. It is worth recalling that Smith et al. [1968] have found an experimental

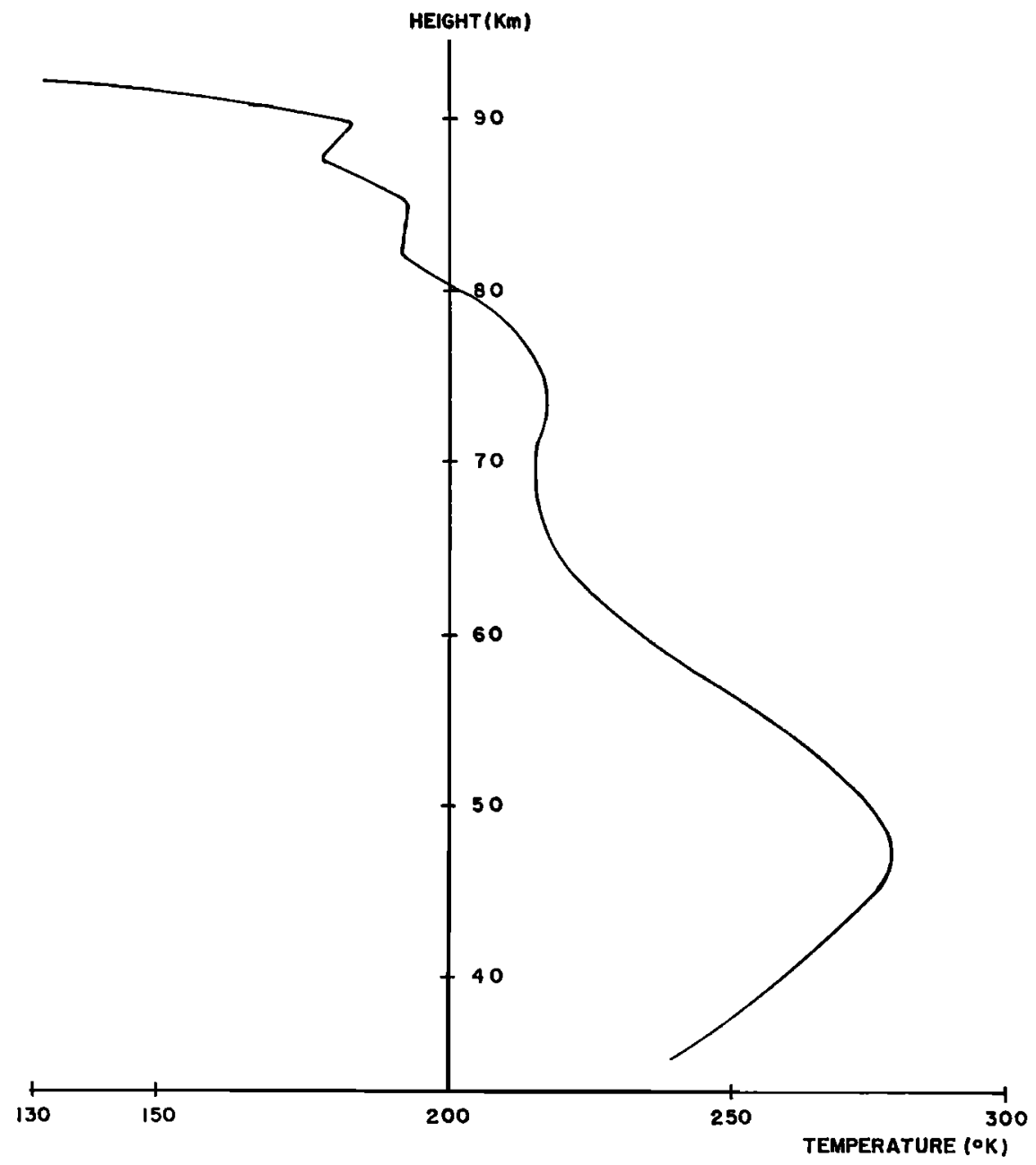

Fig. 5. Temperature-height data from October 2, 1966. Note the minimum of the order of $130^{\circ} \mathrm{K}$ found in the upper mesosphere. The profile was obtained by joining point-by-point instead of being adjusted over the data. 
Fig. 6. Comparison between profiles representing theoretical and experimental sunrisesunset temperatures. Dashed lines represent data from Lindzen's theory; solid lines, Natal experimental data.

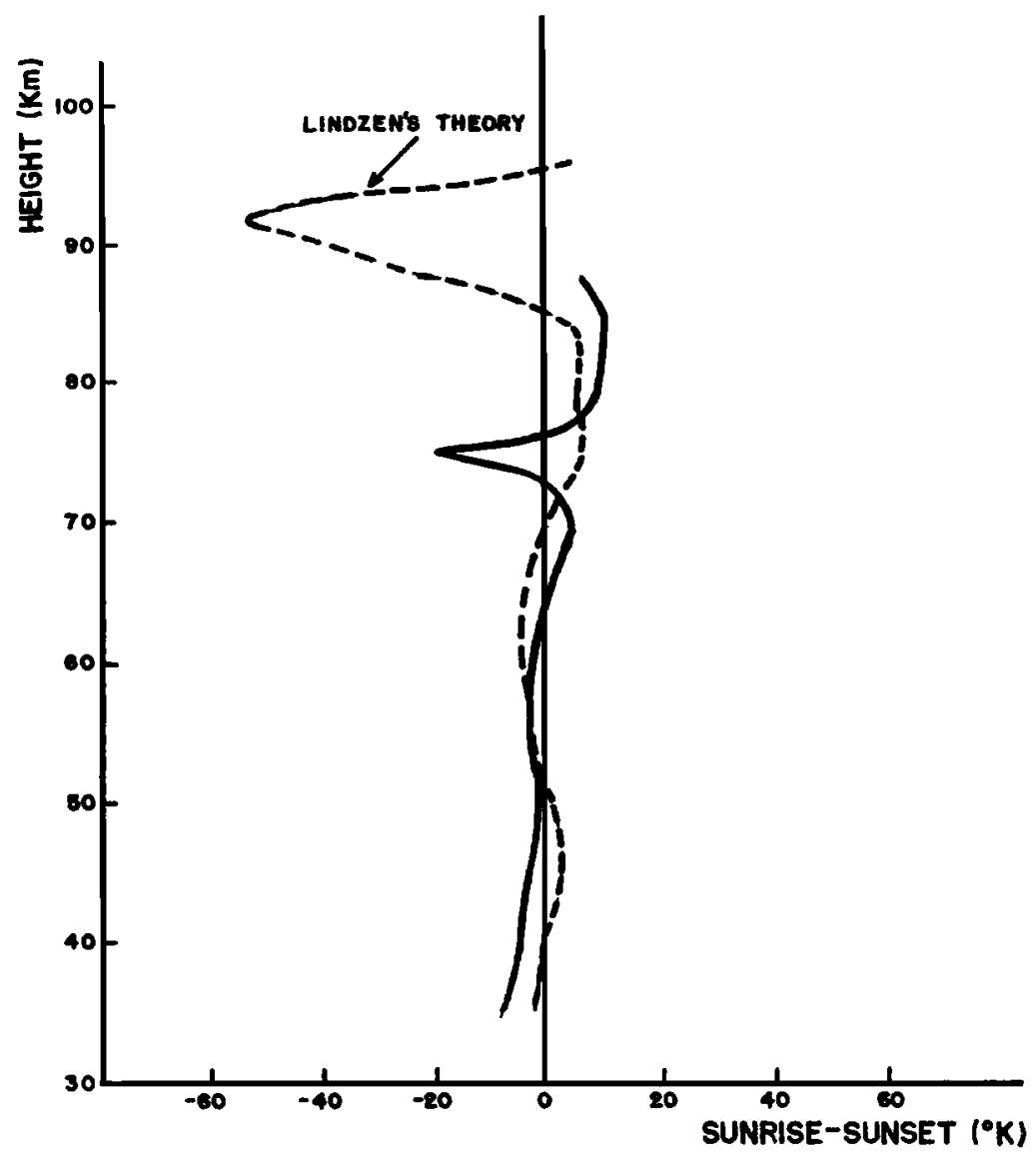

6. PROBABLE EVIDENCE OF A STRATOSPHEREIONOSPHERE COUPLING

To investigate the interaction between the neutral stratosphere and the lower ionosphere, a comparison was made between temperature changes in the stratosphere and the mesosphere and changes in the absorption of cosmic radio noise. The results of the comparison are shown in Figure 7. The comparison was made point-by-point since the data used were not continuous.

The stratosphere-ionosphere coupling may occur in several different ways. The coupling is actually an influence of the changes of some parameters in the mesosphere on the ionosphere, and vice versa. These parameters may be of different natures, e.g. electrical, chemical, mechanical, or meteorological.

An interesting study of a correlation between meteorological parameters was that of Quiroz and Miller [1968], where strong correlations among pressure, density, and temperature in certain height intervals were found. In an attempt to determine the correlation theoretically, Quiroz and Miller used the inte- 


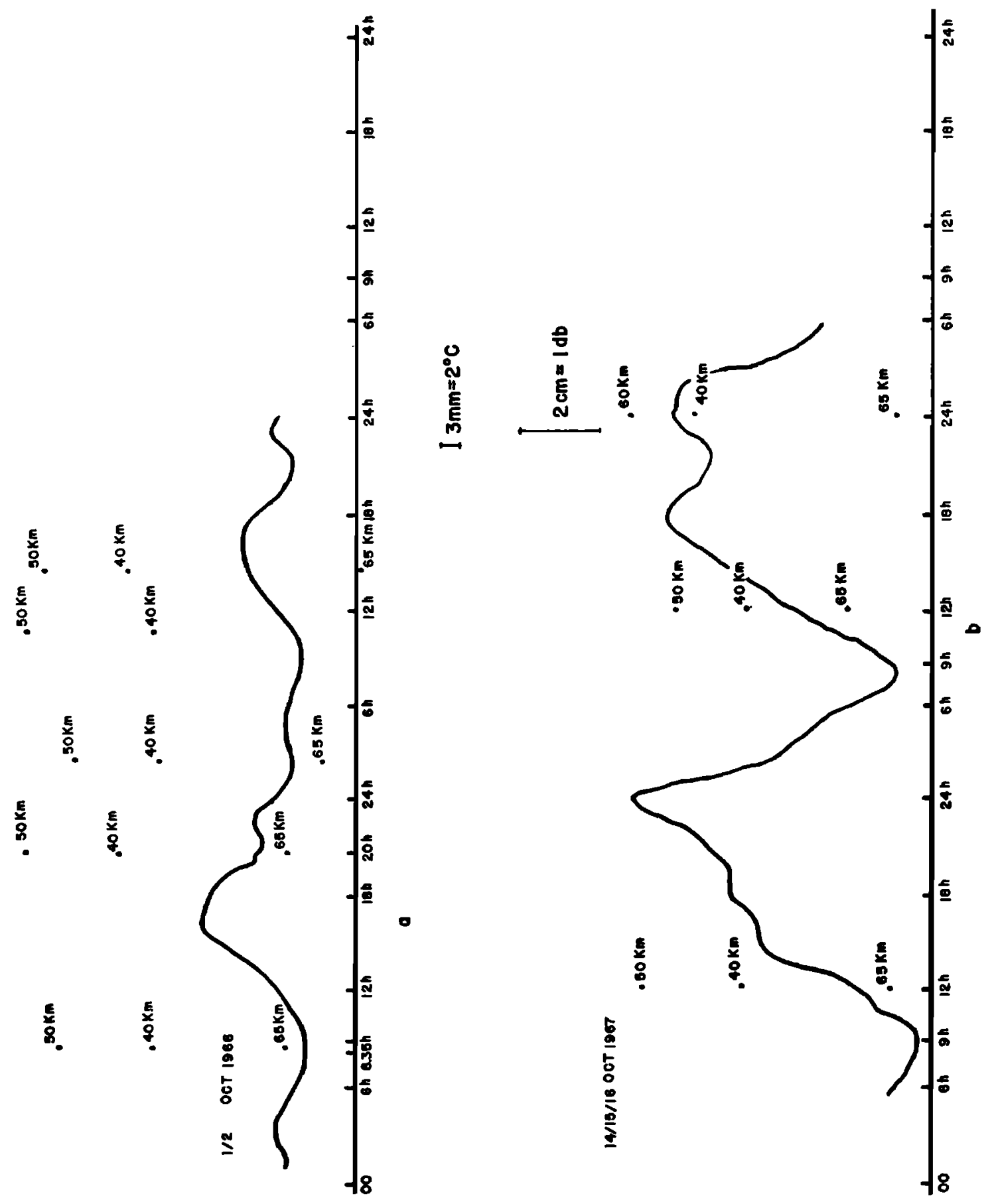



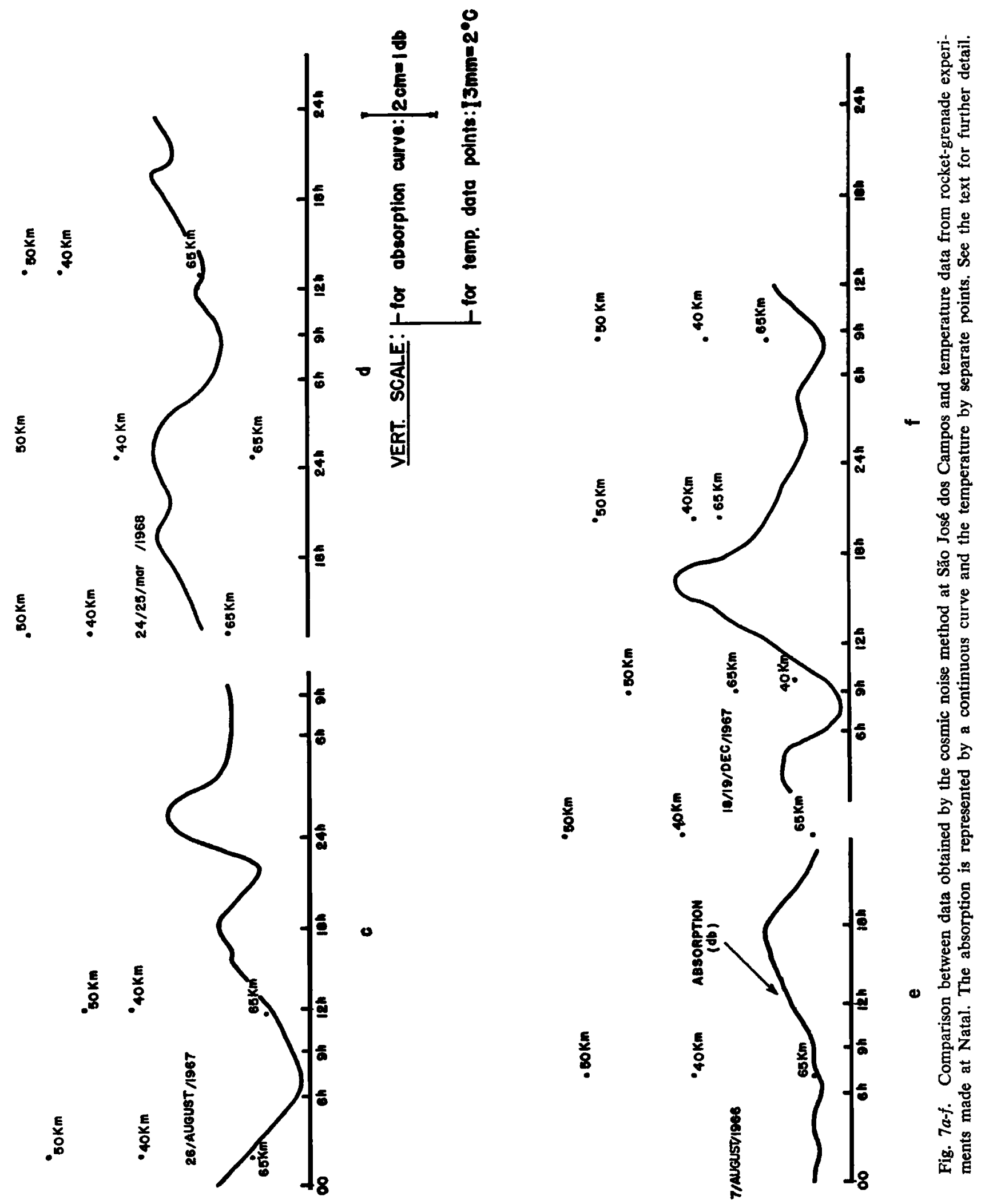
grated hydrostatic equation to derive a formula that fairly well described the dependence of the density on pressure and temperature at lower levels. A surprising feature was the fact that the maximum density-pressure correlation occurred in a height interval equal to the scale height of the considered region. A similar treatment of the problem was given by Heard [1967].

Stratosphere-ionosphere coupling constitutes one of the newest areas of study within the upper atmosphere, for it had not been verified or even suspected until about five years ago. The complexity of the phenomena involved, together with the relative scarcity of complementary data and the short elapsed time from the first experimental verifications of the coupling, made difficult a more precise analysis of the phenomena. These phenomena seem to depend on a set of conditions instead of a direct and clear interaction between the two levels, and consequently they are not well understood in spite of a number of studies [Gregory, 1965; Lauter, 1967; Heard, 1967; Bowhill, 1967].

The correlation between stratospheric temperature and cosmic noise absorption in the lower ionosphere, which is shown in Figure 7, is just one of the multiple aspects of the problem.

In Figure 7 the absorption was plotted against temperatures at 40,50 , and $65 \mathrm{~km}$. We can see that the temperatures at 40 or $50 \mathrm{~km}$ best follow the absorption. It is interesting to note that the temperature at $65 \mathrm{~km}$ is much more variable than the temperatures at 40 and $50 \mathrm{~km}$, as we pointed out in the last section.

The temperatures for 40 and $50 \mathrm{~km}$ for October 1 and 2, 1966, (plot $a$, Figure 7) follow very nearly the variations of absorption. During these two days no sharp variations in absorption were found; the amplitude of variation was about $1.5 \mathrm{db}$ and $12^{\circ} \mathrm{C}$ in absorption and temperature, respectively.

The data for October 14, 15, and 16, 1967 (plot $b$, Figure 7), present four sharp variations. Coincidently, however, the three launchings made during these three days were at times when the absorption levels were relatively close. The amplitude of absorption variation in these three days was about $3.5 \mathrm{db}$. The other four plots $(c, d, e$, and $f$ ) did not show any particularly sharp variations in absorption and temperature. We can observe a fair agreement in the smooth variations.
We must also recall that the temperature observations were taken at Natal $\left(5.9^{\circ} \mathrm{S}, 35.5^{\circ} \mathrm{W}\right)$ and the absorptions were measured at São José dos Campos, $\left(23^{\circ} \mathrm{S}, 45.4^{\circ} \mathrm{W}\right)$. This latitude difference may not be significant for the study of this correlation, however, because in this latitude range the factors that are relevant here, such as heating of the stratosphere, solar zenith angle, collision frequency, and electron concentration variations, have similar behavior. Hence the temperature variations at Natal could approximately represent also the temperature variations at São José dos Campos, or the absorption values at São José dos Campos could similarly represent the ones verified at Natal.

The increase of absorption could be the result of an enhancement of electron concentration or an increase in the electron collision frequency, which in turn could be influenced by the temperature in the stratosphere and mesosphere.

Acknowledgments. We are indebted to our colleagues Clovis S. Pereira, S. R. Friggi, and C. J. Zamlutti, who kindly prepared the absorption data, the computer programs, and the ionospheric data, respectively, that were used in the present work.

\section{REFERENCES}

Bowhill, S. A. (1967), Interactions between the stratosphere and the ionosphere, presented at the IQSY Assembly, London, $A n n$. IQSY, in press.

CIRA (1965), Cospar International Reference Atmosphere, pp. 80-82, North-Holland, Amsterdam.

Gregory, J. B. (1965), The influence of atmospheric circulation on mesospheric electron densities in winter, $J$. Atmos. Sci., 22, 8-23.

Heard, W. C. (1967), Mesospheric Stratospheric Coupling, Scientific Report 297, pp. 1-34, NSF grant GP4622, Ionospheric Research Laboratory, Pennsylvania State University, University Park.

Lauter, E. A. (1967), Present research aspects in ionsphere stratosphere coupling effects, in Space Res., 7, pp. 212226.

Lindzen, R. S. (1967), Thermally driven diurnal tides in the atmosphere, Quart. J. Meteorol. Soc., 93, 18-42.

Nordberg, W., L. Katchen, J. Theon, and W. S. Smith (1965), Rocket observations of the structure of the mesosphere, J. Atmos. Sci., 22, November, 611-622.

Quiroz, R. S., and Alvin J. Miller (1968), Height lag correlations of density with pressure and temperature at rocket altitudes of the stratosphere, J. Atmos. Sci., 25, 104-112.

Smith, W. S., L. B. Katchen, and J. S. Theon (1968), Grenade experiments in a program of synoptic meteorological measurements, Meteorol. Monogr. 9(31), 170175. 